\title{
DISTRIBUSI CAPUNG PADA DAERAH JALUR AIR SUNGAI DI TAMAN WISATA ALAM SURANADI
}

\section{DISTRIBUTION OF DRAGONFLIES IN THE RIVER WATERWAYS IN THE SURANADI NATURAL PARK}

\author{
M. Liwa Ilhamdi ${ }^{1}$, Agil Al Idrus ${ }^{1}$, Didik Santoso ${ }^{1}$ \\ ${ }^{1}$ Dosen Pendidikan Biologi FKIP Universitas Mataram \\ *Email: liwa_ilhamdi@unram.ac.id
}

Diterima: 18 Januari 2019. Disetujui: 18 Januari 2019. Dipublikasikan: 30 September 2019

\begin{abstract}
Abstrak. Capung mempunyai peran penting sebagai bioindikator lingkungan perairan dan warnanya indah sebagai ekowisata sehingga penelitian ini penting dilakukan. Hutan Suranadi dikategorikan sebagai salah satu kawasan yang memiliki keunikan secara bioekologi karena menyediakan tempat hidup bagi berbagai jenis capung. Tujuan penelitian untuk mengetahui distribusi capung di daerah jalur air sungai di Taman Wisata Alam Suranadi. Penelitian dilakukan pada bulan Juni 2019. Metode penelitian yang dilakukan adalah metode survey langsung melalui jalur perairan sungai yang ada di TWA Suranadi. Data di analisis menggunakan uji varians. Hasil penelitian menunjukkan bahwa satu spesies Gynacantha manderica berdistribusi teratur dan 15 spesies lainnya berdistribusi mengelompok.
\end{abstract}

Kata kunci: Distribusi, Capung, Suranadi

Abstrack. Dragonflies have an important role as a bioindicator of the aquatic environment and the beauty of its color for ecotourism so this research is important to do. Suranadi forest is categorized as one of the areas that has bioecological uniqueness because it provides a place to live for various types of dragonflies. The aim this research to determine the distribution of dragonflies in the river waterways in Suranadi Natural Park. The study was conducted in June 2019. The research method carried out was a direct survey method through the river waters in Suranadi Natural Park. Data were analyzed using variance test. The results showed that one species (Gynacantha manderica) distribution pattern is regular and 15 other species distribution pattern is groups

Keywords: Distribution, Dragonflies, Suranadi

\section{PENDAHULUAN}

Capung mempunyai banyak spesies, beragam warna yang menarik dan variasi ukuran. Capung merupakan kelompok serangga yang daur hidupnya terutama pada saat bertelur dan fase nimfa capung menghabiskan kehidupannya di daerah perairan yang sehat. Kehadiran capung dapat menandakan bahwa di sekitar lingkungan tersebut terdapat air bersih (Budianta, 2011).

Capung hidup pada habitat perairan seperti sawah, sungai, danau, kolam, atau hutan yang mempunyai sungai atau mata air (Sachran, 2012). Salah satu kawasan hutan yang berperan penting dalam mendukung kehidupan capung ialah Kawasan Hutan wisata alam Sesaot yang merupakan hutan dengan banyak sumber mata air dan sumber air untuk sebagian besar wilayah pulau Lombok.

Kehadiran capung sangat dipengaruhi oleh kondisi lingkungan yang meliputi lingkungan air dan struktur hutan karena air yang tercemar akan mengganggu kehidupan nimfa capung, begitu juga dengan hutan, hutan yang heterogen memiliki kemelimpahan populasi capung yang lebih tinggi. Keanekaragaman capung yang tinggi pada suatu kawasan mengindikasikan kawasan tersebut belum tercemar karena lingkungan tersebut mendukung kehidupan nimfa capung (Ansori, 2009).

Jhon (2001) dalam Sachran (2012), menyatakan tanpa kehadiran serangga seperti capung, maka kehidupan suatu ekosistem akan terganggu dan tidak akan mencapai suatu keseimbangan. Shanti (1998) menyatakan bahwa capung dapat dijadikan sebagai indikator air bersih yang bermanfaat untuk memonitor kualitas air di sekitar lingkungan. Secara tidak langsung kehadiran capung dapat menandakan bahwa di sekitar lingkungan tertentu terdapat air bersih, karena capung tidak akan hidup pada air yang sudah tercemar. Oleh sebab itu perubahan dalam populasi capung dapat dijadikan sebagai langkah awal untuk menandai adanya polusi. Aktivitas capung sebagian besar dilakukan pada siang hari, sehingga capung sangat sulit untuk didekati karena capung terbang sangat lincah dibandingkan pada dini hari maupun sore hari.

Salah satu hutan yang banyak ditemukan capung adalah hutan Suranadi. Hutan Suranadi ditetapkan sebagai Taman Wisata Alam dengan luas 52 ha berdasarkan SK Mentri Pertanian tanggal 15 Oktober 1976 Nomor: 274/Kpts/UM/5/77. Selama ini bagaimana Distribusi capung di hutan Suranadi 
belum pernah diteliti dan dipublikasikan mengingat pada saat ini kerusakan hutan dan perburuan capung terjadi secara besar-besaran.

Berdasarkan hal tesebut maka analisis distribusi capung tersebut sangat penting sebagai data dasa dan bahan pertimbangan dalam memformulasikan strategi konservasinya, khususnya di hutan Suranadi dan pulau Lombok pada umumnya. Selain itu, informasi ini juga dapat dimanfaatkan oleh siswa-siswi maupun pendidik di sekolah sebagai salah satu sumber atau media pembelajaran biologi yang khususnya sedang mempelajari bab keanekaragaman hayati dimana selama ini sumber atau media belajar masih berasal dari hasil teori-teori yang ada karena masih kurangnya sumber atau media yang berasal dari hasil penelitian. Oleh karena itu dilakukan penelitian tentang Distribusi capung pada daerah jalur air sungai di taman wisata alam suranadi.

Distribusi suatu jenis di komunitasnya dapat memberikan gambaran hubungan antar jenis, dan bentuk distribusi suatu hewan di habitatnya. Individu-individu yang ada di dalam populasi mengalami penyebaran di dalam habitatnya mengikuti salah satu di antara tiga distribusi yang disebut pola distribusi intern (Indriyanto, 2006). Menurut Odum (1993), tiga pola distribusi intern yang dimaksud antara lain distribusi acak (random), distribusi seragam (uniform), dan distribusi bergerombol (clumped). Distribusi acak terjadi apabila kondisi lingkungan seragam, tidak ada kompetisi yang kuat antarindividu anggota populasi, dan masing-masing individu tidak memiliki kecenderungan untuk memisahkan diri (Indriyanto, 2006). Distribusi seragam terjadi apabila kondisi lingkungan cukup seragam di seluruh area dan ada kompetensi yang kuat antarindividu anggota populasi. Kompetisi yang kuat antarindividu anggota populasi akan mendorong terjadinya pembagian ruang yang sama (Indriyanto, 2006). Distribusi bergerombol pada suatu populasi merupakan distribusi yang umum terjadi di alam, baik bagi tumbuhan maupun bagi binatang (Indriyanto, 2006). Menurut Heddy dalam Indriyanto (2006) distribusi bergerombol terjadi karena berbagai sebab antara lain sebagai berikut: kondisi lingkungan jarang yang seragam, meskipun pada areal sempit. Pola reproduksi dari suatu individu-individu anggota populasi. Perilaku hewan yang cenderung membentuk kesatuan yang mendorong terjadinya distribusi bergerombol. Demikian juga daya tarik seksual bagi binatang merupakan kekuatan yang mendorong terjadinya distribusi bergerombol. Di dalam Distribusi bergerombol ternyata tiap-tiap kelompok ada kemungkinan tersebar secara acak, seragam, ataupun secara berkumpul. Oleh karena itu, tipe distribusi secara keseluruhan dapat terjadi: secara acak, seragam, bergerombol secara acak, bergerombol secara seragam, dan bergerombol berkumpul (Odum, 1993). Lebih lanjut dikemukakan bahwa agregasi atau penggerombolan individu-individu organisme anggota populasi terjadi akibat beberapa hal, antara lain: (1) menanggapi adanya perubahan cuaca harian atau musiman; (2) menanggapi perbedaan kondisi habitat setempat; (3) sebagai akibat dari proses reproduksi; (4) sebagai akibat daya tarik sosial.

Tujuan penelitian ini adalah untuk mengetahui distribusi capung di daerah jalur air sungai di Taman Wisata Alam Suranadi. Adapun hasil dari penelitian ini diharapkan mempunyai manfaat sebagai informasi dasar untuk keperluan penelitian dan pelestarian capung di kawasan hutan Taman Wisata Alam Suranadi. Sebagai bahan informasi kepada masyarakat sekitar kawasan hutan Taman Wisata Alam Suranadi agar mendukung dan membantu kelestarian potensi alam yang ada. Dengan adanya penelitian ini diharapkan pelestarian kawasan hutan Taman Wisata Alam Suranadi dapat terus terjaga untuk kelestarian ekosistem yang ada di sekitarnya.

\section{METODE DAN BAHAN}

Jenis penelitian ini adalah deskriptif eksploratif. Pendekatan yang digunakan dalam

penelitian ini adalah observasi di lapangan dan laboratorium untuk memperoleh gambaran tentang Distribusi capung di daerah jalur air kawasan hutan Taman Wisata Alam Suranadi.

Penelitian ini dilakukan di kawasan hutan Taman Wisata Alam Suranadi, Desa Suranadi, Kecamatan Narmada, Kabupaten Lombok Barat, Provinsi Nusa Tenggara Barat selama 6 minggu. Pengambilan sampel dilakukan satu kali dalam seminggu yaitu mulai dari pukul $08.00-17.00$ WITA. Identifikasi sampel dilakukan di Laboratorium Biologi FKIP Universitas Mataram.

Alat dan bahan yang akan digunakan dalam penelitian ini adalah sebagai berikut: 
Tabel 1. Alat dan bahan penelitian

\begin{tabular}{|c|c|c|c|}
\hline No & Nama alat/bahan & Jumlah & Kegunaan \\
\hline 1 & $\begin{array}{l}\text { Jaring serangga } \\
\text { (sweeping net) }\end{array}$ & 1buah & Untuk menangkap capung. \\
\hline 2 & Kertas papilot & $\begin{array}{l}\text { Sesuai dengan jumlah } \\
\text { capung yang } \\
\text { tertangkap }\end{array}$ & $\begin{array}{l}\text { Sebagai tempat capung ketika baru } \\
\text { ditangkap agar sayapnya tidak rusak. }\end{array}$ \\
\hline 3 & Pinset & 2 buah & $\begin{array}{l}\text { Untuk menata capung ketika dibuat } \\
\text { spesimen keringnya. }\end{array}$ \\
\hline 4 & Jarum suntik & 1buah & $\begin{array}{l}\text { Untuk menyuntikkan alkohol ke dalam } \\
\text { tubuh capung. }\end{array}$ \\
\hline 5 & Jarum pentul & 1 box kecil & $\begin{array}{l}\text { Sebagai penusuk capung pada papan } \\
\text { perentang. }\end{array}$ \\
\hline 6 & Kotak spesimen & 1buah & $\begin{array}{l}\text { Untuk menyimpan capung setelah } \\
\text { ditangkap. }\end{array}$ \\
\hline 7 & Steroform & 1buah & $\begin{array}{l}\text { Sebagai tempat meletakkan capung } \\
\text { ketika membuat spesimen keringnya. }\end{array}$ \\
\hline 8 & Kaca pembesar & 1buah & $\begin{array}{l}\text { Memperjelas bagian tubuh capung } \\
\text { sehingga mempermudah dalam melakukan } \\
\text { identifikasi. }\end{array}$ \\
\hline 9 & Kamera & 1buah & Sebagai alat dokumentasi. \\
\hline 10 & Alat-alat tulis & 1 set & $\begin{array}{l}\text { Untuk keperluan pemberian label dan lain- } \\
\text { lain. }\end{array}$ \\
\hline 11 & $\begin{array}{l}\text { Buku identifikasi } \\
\text { capung }\end{array}$ & 3 macam & Untuk mengidentifikasi spesies capung. \\
\hline 12 & $\begin{array}{l}\text { Capung hasil } \\
\text { tangkapan }\end{array}$ & $\begin{array}{l}\text { Sesuai dengan jumlah } \\
\text { capung yang } \\
\text { tertangkap }\end{array}$ & Sebagai bahan penelitian. \\
\hline 13 & Formalin 4\% & 1 liter & Untuk mengawetkan capung. \\
\hline 14 & Millimeter blok & 1 lembar & Untuk mengetahui ukuran capung \\
\hline
\end{tabular}

Metode pengambilan sampel capung dilakukan dengan metode survey. Penangkapan capung dilakukan dengan menggunakan teknik sweeping dengan mengikuti jalur transek yang telah ditentukan berdasarkan hasil observasi. Capung ditangkap dengan jaring serangga. Pengkoleksian capung dilakukan mulai pukul 08.00 sampai 12.00 WITA, dan sore hari dimulai dari pukul 15.00 sampai 17.00 WITA sekali dalam seminggu selama enam minggu. Pemilihan waktu penelitian berdasarkan waktu aktifnya capung. Jenis-jenis capung yang belum bisa dipastikan jenisnya, dimasukkan ke dalam kertas papilot. Setiap kertas papilot yang di dalamnya terdapat spesies capung diberi kode abjad atau angka untuk membedakan spesies yang satu dengan yang lainnya. Capung yang telah dimasukkan ke dalam kertas papilot dimasukkan ke dalam kotak koleksi supaya tidak rusak atau patah. Setelah itu sampel yang didapat dibawa ke laboratorium untuk dibuat spesimen keringnya untuk selanjutnya diidentifikasi menggunakan buku identifikasi capung.
Distribusi masing-masing spesies capung dapat menggunakan rumus nilai varians dari Southwood dalam Ludwig (1988) sebagai berikut:

$$
\text { dimana } \left.\quad \bar{A}=\left(\sum x\right) / n\right) \quad S^{2}=-\sum(x-\bar{A})^{2}
$$

Keterangan: $\quad \mathrm{x} \quad$ : Jumlah individu tiap spesies

$\mathrm{n} \quad$ :Jumlah jalur pengamatan

$\overline{\mathrm{A}} \quad$ :Rata-rata jumlah individu

tiap jalur

Indikator pola distribusi atau penyebaran capung sebagai berikut : jika $\mathrm{S}^{2}<\overline{\mathrm{A}}$ maka Distribusinya secara teratur, jika $\mathrm{S}^{2}=\overline{\mathrm{A}}$ penyebarannya secara acak dan jika $\mathrm{S}^{2}>\overline{\mathrm{A}}$ penyebarannya secara berkelompok.

\section{HASIL DAN PEMBAHASAN}

Hasil analisis data hasil penelitian menunjukkan bahwa Distribusi untuk masing-masing jenis capung di kawasan hutan TWA Suranadi secara umum mengelompok dengan nilai lebih besar dibandingkan 
dengan nilai rata-rata jumlah individu capung kecuali

Gynacantha manderica Distribusi teratur (tabel 2).

Tabel 2. Distribusi masing-masing spesies capung yang ada di daerah Jalur air Sungai Taman Wisata Alam Suranadi

\begin{tabular}{|c|c|c|c|}
\hline No. & Spesies Capung & $\mathbf{S}^{2}$ & Distribusi \\
\hline 1 & Agriocnemis femina & 12 & Mengelompok \\
\hline 2 & Copera marginipes & 16207 & Mengelompok \\
\hline 3 & Diplacodes trivialis & 3 & Mengelompok \\
\hline 4 & Lathrecista asiatica & 36.75 & Mengelompok \\
\hline 5 & Libellago lineata & 31.69 & Mengelompok \\
\hline 6 & Neurothemis fluctuans & 1.688 & Mengelompok \\
\hline 7 & Neurothemis ramburii & 468.8 & Mengelompok \\
\hline 8 & Orthetrum chrysis & 841.7 & Mengelompok \\
\hline 9 & Orthetrum sabina & 379.7 & Mengelompok \\
\hline 10 & Pantala flavescens & 6.75 & Mengelompok \\
\hline 11 & Pseudagrion pilidorsum & 1027 & Mengelompok \\
\hline 12 & Pseudagrion pruinosum & 48 & Mengelompok \\
\hline 13 & Trithemis furva & 9.188 & Mengelompok \\
\hline 14 & Gynacantha manderica & 0.188 & Teratur \\
\hline 15 & Zyxomma obtusum & 697.7 & Mengelompok \\
\hline 16 & Zyxomma petiolatum & 1027 & Mengelompok \\
\hline
\end{tabular}

Menurut Odum (1993) sifat penyebaran merata atau teratur dapat dimungkinkan terjadi adanya persaingan antar individu, baik dalam hal ruang atau makanan. Interaksi ini mendorong pembagian ruang yang sama. Sifat penyebaran mengelompok umumnya dimiliki oleh serangga karena kecenderungan untuk mengelompok, berkumpul dari berbagai derajat mewakili sifat yang paling umum. Berdasarkan hasil perhitungan Varians $\left(\mathrm{S}^{2}\right)$ dan jumlah jenis dalam sampel maka sifat penyebaran capung dari tiap famili adalah berkelompok. Lebih lanjut Odum (1993) mengemukakan bahwa pengelompokan individuindividu organisme anggota populasi terjadi akibat beberapa hal, antara lain: menanggapi adanya perubahan cuaca harian atau musiman, menanggapi perbedaan kondisi habitat setempat, sebagai akibat dari proses reproduksi, sebagai akibat daya tarik sosial.

Adapun jumlah spesies capung yang ditemukan di TWA Suranadi berjumlah 16 spesies. Hal serupa telah dilakukan penelitian oleh Hidayah (2008) di Kebun Raya Bogor menemukan sepuluh spesies capung. Neldawati (2011) penelitian di kawasan Resort Gunung Tujuh Taman Nasional Kerinci Seblat Kabupaten Kerinci Provinsi Jambi menemukan 22 jenis yang terdiri dari 14 genera. Emrades (2008) melakukan penelitian mengenai jenis-jenis capung (Odonata) di hutan pendidikan dan penelitian biologi Universitas dan Penelitian Biologi Universitas Andalas Padang. Hasil penelitiannya diperoleh capung yang terdiri dari dua subordo, tujuh famili, 18 genera, 23 spesies, dan 135 individu. Penelitian lainnya yang dilakukan oleh Simanjuntak 
J. Pijar MIPA, Vol. 14 No.3, September 2019: 202-207 DOI: $\underline{10.29303 / \mathrm{jpm} . v 14 \mathrm{i} 3.1000}$

(2009) di Kawasan Cagar Alam Pegunungan Wondiboi Distrik Rasiei Kabupaten Teluk Wondama. Penelitian bertujuan menginventarisasi spesies capung yang berada di sekitar Kawasan Cagar Alam Pegunungan Wondiboi di Distrik Rasiei Kabupaten Teluk Wondama. Pengamatan dilakukan pada tiga tipe habitat yaitu hutan sekunder, pemukiman dan hutan primer. Metode yang digunakan dalam penelitian ini adalah dengan teknik observasi lapangan. Data dikumpulkan dan dianalisis secara deskriptif. Hasil penelitian, menunjukkan baTWA di jumpai sebanyak 14 spesies capung.

Dalzochio et al. (2011) menemukan 33 jenis yang termasuk dalam 5 famili capung di hutan alam Serra da Bodoquena, Brazil. Jumlah jenis yang lebih sedikit ditemukan pada kawasan hutan mangrove Muthupet, Tamil Nadu India yaitu 8 jenis yang termasuk dalam 2 famili (Muthukumaravel, 2015). Dayakrishna dan Arya (2015) menemukan 420 individu terdiri atas 19 jenis yang termasuk ke dalam 4 famili capung di Uttarakhand, India. Manwar et al. (2012) juga menemukan 22 jenis dari 4 famili di hutan lindung Malkhed, India; 20 jenis yang termasuk dalam 4 famili di Hutan Gugur Thoothukudi, India Selatan 34 jenis yang termasuk dalam 4 famili di Biopark Internasional Gorewada Nagpur, India Tengah (Shende, 2013).

Perbedaan jumlah individu Odonata ini diduga karena pengaruh faktor kualitas lingkungan suatu habitat, seperti $\mathrm{pH}$, temperatur, kelembaban udara, kondisi faktor kimia, dan ketersediaan makanan (Anshori, 2009).

\section{KESIMPULAN DAN SARAN}

Berdasarkan hasil penelitian dapat disimpulkan bahwa Distribusi capung di TWA Suranadi termasuk mengelompok, kecuali Gynacantha manderica memiliki distribusi teratur. Dari hasil penelitian disarankan agar perlu konservasi dan pengembangan capung di Taman Wisata Alam Suranadi sebagai sumber belajar bagi siswa dan dapat dijadikan sebagai ekowisata di Lombok Barat NTB

\section{DAFTAR PUSTAKA}

Ansori, I. 2009. Kelimpahan dan Dinamika Populasi Odonata Berdasarkan Hubungannya dengan Fenologi Padi di Beberapa Persawahan sekitar Bandung Jawa Barat.Jurnal exacta, 7(2): 67-75.

Budianta, E. 2011.Capung Teman Kita; Pelestarian Odonata sebagai Pusaka Alam Indonesia. Jakarta: Bayu Media.
Dalzochio, M.S., Costa, J.M., and Uchôa, M.A. 2011. Diversity of Odonata (Insecta) in lotic systems from Serra da Bodoquena, Mato Grosso do Sul State, Brazil. Revista Brasileira de Entomologia Vol. 55(1): 88-94

Dayakrishna, Arya, M.K. 2015. Study on the abundance and diversity of dragonflies and damselflies (Insecta: Odonata) of Corbett Tiger Reserve, Uttarakhand, India. Journal of Entomology and Zoology Studies Vol. 3(4): 467-472

Hidayah, Siti Nurul Indah. 2008. Keanekaragaman dan aktivitas Capung (ordo : odonata) di kebun raya bogor. Skripsi Mahasiswa Program Studi Ilmu Hama \& Penyakit Tumbuhan Fakultas Pertanian Institut Pertanian Bogor

Indriyanto, 2006, Ekologi Hutan, Bumi Aksara , Jakarta.

Kannagi, A., Sivakumar, V., Santhi, V. 2016. Diversity of Dragonflies (Insecta: Odonata) in a Deciduous Forest of Thoothukudi District, Tamil Nadu, South India. International Journal of Environmental Protection and Policy Vol. 4(3): 5863

Manwar, N.A., Rathod, P.P., and Raja, I.A. 2012. Diversity and abundance of Dragonflies and Damselflies Of Chatri Lake Region, in Pohara Malkhed Reserve Forest, Amravati, Maharashtra (India). IJERA Vol. 2(5): 521-523

Muthukumaravel, K., Raja, R.B., , Amsath, A., S. Prabakaran2 and Y. Chezhian. 2015. Seasonal variation of dragonflies diversity in Muthupet mangrove forest, Tamil Nadu, India. International Journal of Pure and Applied Zoology Vol. 3 (2): 188192

Neldawati. 2011. Jenis-jenis Capung (Odonata) di Kawasan Resort Gunung Tujuh Taman Nasional Kerinci Seblat Kabupaten Kerinci Provinsi Jambi. Skripsi Mahasiswa Biologi Fakultas Matematika dan Ilmu Pengetahuan Alam, Universitas Andalas, Padang

Odum, E.P. 1993. Dasar-Dasar Ekologi. Tjahjono Samingan (penerjemah).1993. Yogyakarta: Gadjah Mada University Press.

Schran, A., Musdalifah, P.W dan Singgih, K.D. 2012.Jenis-jenis Capung Sekitar Sungai Tadah Angin 
Cagar Alam dan Taman Wisata Pangandaran, Jawa Barat.Jurnal Biologi Universitas Negeri Jakarta, 2(1): 31-36.

Shanti S. 1998. Mengenal Capung. Bogor: Puslitbang LIPI. Sigit, Wahyu, dkk. 2013. Naga Terbang Wendit. Malang: Indonesia Dragonfly Society. 52

Shende,V.A., and Patil, K.G. 2013. Diversity of dragonflies (Anisoptera) in Gorewada International Bio-Park, Nagpur, Central India. Arthropods, Vol. 2(4): 200-207

Simanjuntak, Angginta Renta. 2009. Inventarisasi Spesies Capung (Odonata) di Kawasan Cagar Alam Pegunungan Wondiboi Distrik Rasiei Kabupaten Teluk Wondama. Skripsi Mahasiswa Biologi Fakultas Matematika dan Ilmu Pengetahuan Alam, Universitas Negeri Papua Manokwari. 